\title{
CONGENITAL COMPLETE HEART BLOCK IN DOWN SYNDROME: A RARE CASE REPORT
}

Vishwanath Machakanur ${ }^{1}$

\section{HOW TO CITE THIS ARTICLE:}

Vishwanath Machakanur. "Congenital Complete Heart Block in Down Syndrome: A Rare Case Report". Journal of Evolution of Medical and Dental Sciences 2015; Vol. 4, Issue 47, June 11; Page: 8254-8257,

DOI: $10.14260 /$ jemds/2015/1197

\begin{abstract}
Down syndrome (Trisomy 21) is the commonest disorder among chromosomal anomalies having incidence of 1:650-1:1000 live births.[1] The clinical manifestations of Down syndrome are numerous and can present in any body system. Down association of congenital heart disease is well known. Among all cases of congenital heart diseases, 4\%-10\% are with Down syndrome, and 40\%-60\% of Down syndrome patients have congenital heart disease. The most common congenital cardiac anomaly in Down syndrome is Atrioventricular septal defects, followed by patent ductus arteriosus and atrial septal defects. Other forms of complex heart disease can occur including overriding aorta and Tetralogy of fallot.[2] The pure Conduction defect are very rare to have association with the Down syndrome and is not reported in infancy so far.
\end{abstract}

KEYWORDS: Down syndrome, $3^{\text {rd }}$ degree heart block, congenital heart defects, electrocardiogram (ECG).

CASE REPORT: A 2 month old male baby was brought to our hospital from the periphery with complaint of not feeding well since past 3 days. The baby was the only child, born of $2^{\text {nd }}$ degree consanguineous marriage. On examination he was dysmorphic [Figure 1] with flat facies, mongoloid slants, hypertelorism, epicanthal folds, microcephaly, flat occiput, depressed nasal bridge, clenodactyly and saddle toes indicating Down syndrome clinically. His heart rate was only 26bpm and was always $<50 \mathrm{bpm}(20-30 \mathrm{bpm}$ range) indicating bradyarrhythmia. His ECG showed discordance between p-waves and QRS-complex; atrial heart rate was $100 \mathrm{bpm}$ (p-waves) \& ventricular rate was 26bpm (QRS-complex) [Figure 2]. There was definitive variation of heart rates (ventricular) while sleeping and while crying.

There were no findings in systemic examinations. Chest x-ray was normal, 2D-echo revealed ostium secondum-ASD. Baby was treated with Atropine boluses till pacemaker was put. And Mother's anti Ro antibody were negative ruling out maternal SLE causing congenital heart block. Baby was planned to put a permanent pacemaker but parents could not afford to it and baby was taken against medical advice.

DISCUSSION: The characteristic heart defects in Down syndrome derives from the abnormal development of endocardial cushions and results in a spectrum of defects involving the atrioventricular septum and valves. Accounting for approximately $63 \%$ of all DS-CHD, their lesion varies in severity from persistent of the common atrioventricular canal and membranous ventricular septal defects to ostium primum patency with valvular anomalies.[3] Between 40 and $60 \%$ of babies with Down's syndrome have congenital heart defects. Of these $30-40 \%$ are complete atrioventricular septal defects (AVSD) ${ }^{[4,5,6]}$ The isolated $3^{\text {rd }}$ degree or complete heart block with or without CHD is a rare finding in Down cases. 
A $3^{\text {rd }}$ degree heart block can be congenital or acquired. It has a characteristic of discordance between $p$-waves \& QRS-complexes with regular p-p interval having rate comparable to normal heart rate for patient's age; regular QRS-complexes with a rate much slower than p-rate. In congenital heart block, duration of the QRS-complex is normal, and has a ventricular rate bit higher than that of acquired one. Also, ventricular rate varies in response to varying physiological conditions.

Common causes for congenital complete heart block in infants being, as an isolated anomaly, with congenitally corrected transposition of great arteries, maternal diseases like systemic lupus erythematosis, Sjögren's syndrome or there connective tissue disorders. Causes of acquired complete heart block are: cardiac surgery (the most common cause), severe myocarditis, mumps, diphtheria, cardiomyopathies, myocardial infarction, certain drug overdoses, Lyme carditis etc.

Infants present with congestive cardiac failure when there is associated heart anomaly. Isolated congenital heart block cases may be asymptomatic and achieve normal growth \& development for 5-10years.

Atropine or isoproterenol is indicated in symptomatic cases until temporary ventricular pacing is secured.

No treatment is required for children with asymptomatic congenital complete heart block with acceptable rate, narrow QRS-complex \& normal ventricular function.

\section{Pacemaker therapy is indicated if:}

1. Symptomatic or develops CHF.

2. With ventricular arte of less than 50-55bpm.

3. With congenital heart defect with ventricular rate less than $70 \mathrm{bpm}$.

4. Has wide QRS-escape-rhythm, complex ventricular ectopy, or ventricular dysfunction.

CONCLUSION: Down syndrome with CHD can have $3^{\text {rd }}$ degree/complete heart block and may need cardiac pacing.

LONG TERM PROGNOSIS: In down syndrome the survival beyond one year of age is $85 \%$ and average life expectancy is 40 years in more than $50 \%$ cases.

Congenital heart disease is the most common causes of death in early childhood especially less than 2years of age. The life expectancy has been increasing even with cardiac and other anomalies as there is increased recent advances in management in medical field. [7]

\section{REFERENCES:}

1. Hassold TA, and Sherman S. Down syndrome; Genetic recombination and origin of the extra chromosome 21. Clin Genet, 2000; 57: 95-100.

2. Berr $\mathrm{C}$ and Borghi E. Risk of Down syndrome in relatives of trisomy 21 children. A case-control study. Ann Genet 1990; 33: 137-40.

3. Cooney TP, Thurlbeck WM. Pulmonary hypoplasia in Down's syndrome. N Engl J Med 1982; 307: 1170-73.

4. Frid C, Drott P, Lundell B, Rasmussen F, Anneren G. Mortality in Down's syndrome in relation to congenital malformations. J Intellect Disabil Res 1999 Jun; 43 (Pt 3): 234-41. 


\section{CASE REPORT}

5. Torfs CP, Christianson RE. Anomalies in Down syndrome individuals in a large population based registry. Am J Med Genet 1998 Jun 5; 77(5): 431-8.

6. Tubman TR, Shields MD, Craig BG, Mulholland HC, Nevin NC. Congenital heart disease in Down's syndrome: two year prospective early screening study. BMJ 1991 Jun 15; 302(6790): 1425-7.

7. Cincinnati Children's hospital medical Center. Down syndrome (Trisomy 21). 2009: 1-4. www.cincinnatichildrens.org/health/d/down.

Fig. 1: Dysmorphic features of the baby (flat facies, mongoloid slants, hypertelorism, epicanthal folds, microcephaly, flat occiput, depressed nasal bridge).

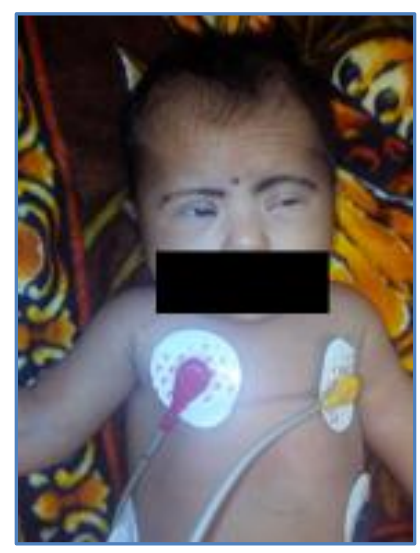

\section{Fig. 1}

ECG pattern of the baby indicating $3^{\text {rd }}$ degree heart block.

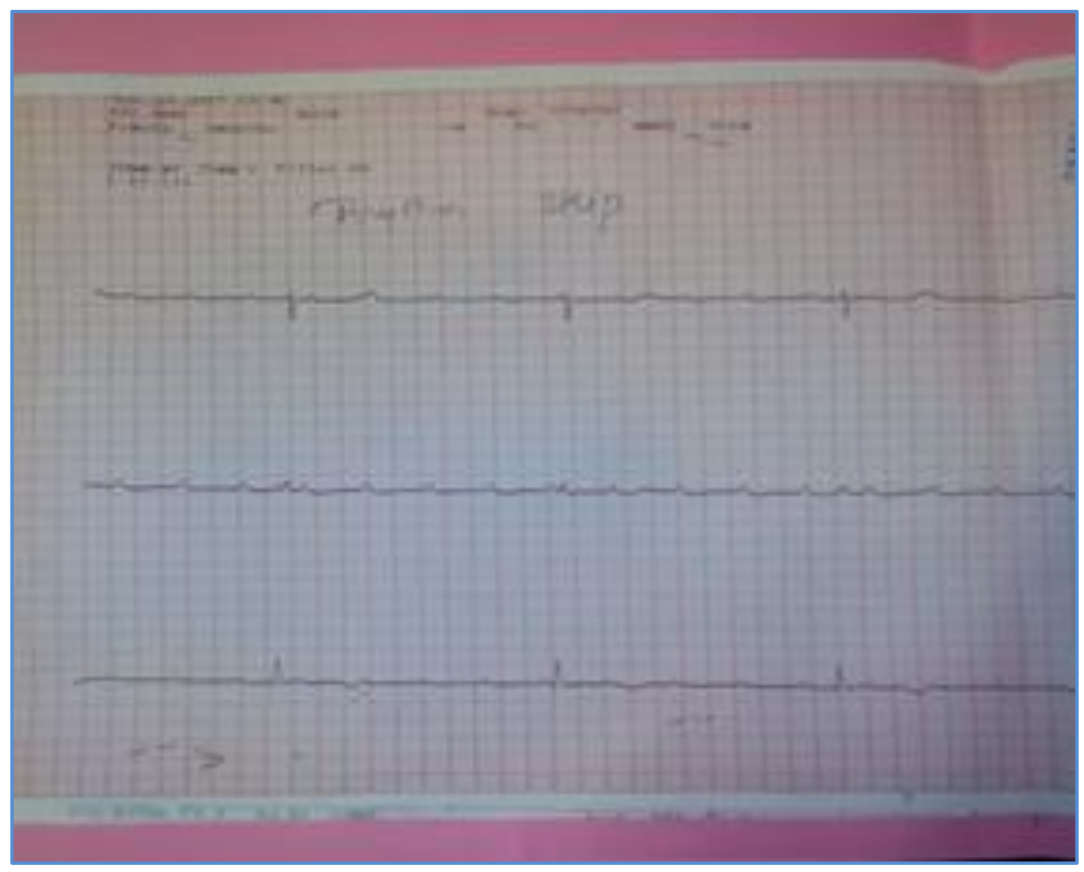

Leads I, II, III 


\section{CASE REPORT}

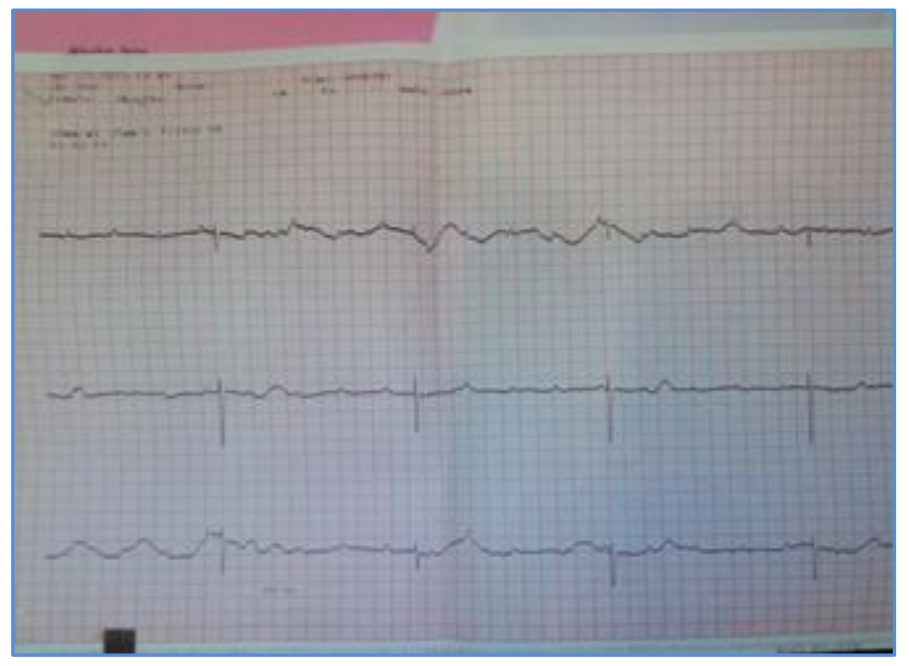

Leads V1, V2, V3

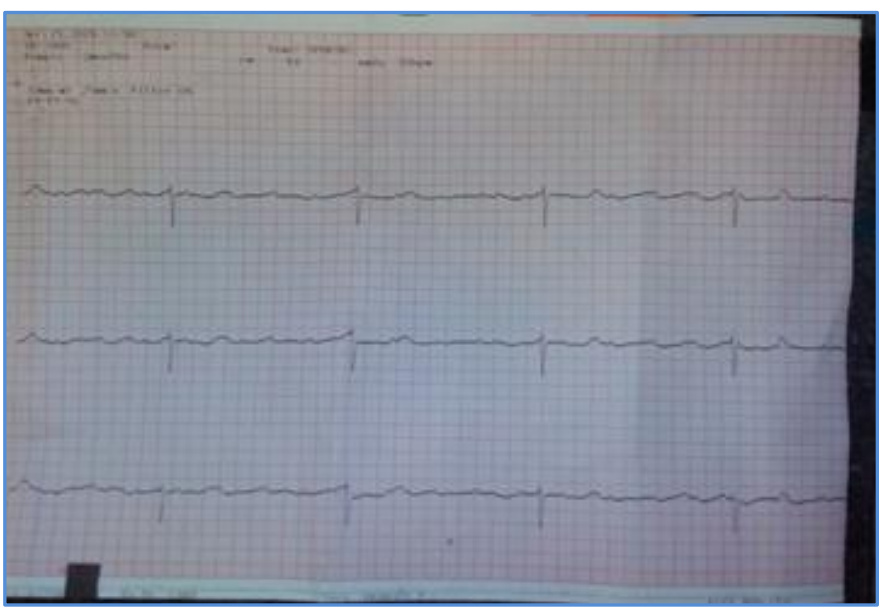

Leads V4, V5, V6

\section{AUTHORS:}

1. Vishwanath Machakanur

\section{PARTICULARS OF CONTRIBUTORS:}

1. Assistant Professor, Department of Paediatrics, J. N. Medical College, Belagavi, Karnataka.

\section{FINANCIAL OR OTHER} COMPETING INTERESTS: None
NAME ADDRESS EMAIL ID OF THE CORRESPONDING AUTHOR:

Dr. Vishwanath Machakanur,

"Chandra-Kamala",

Plot No. 39A, P \& T Colony, $2^{\text {nd }}$ Stage, Hanuman Nagar,

Belgaum-590019.

E-mail: vlmjnmc@gmail.com

Date of Submission: 20/05/2015.

Date of Peer Review: 21/05/2015.

Date of Acceptance: 04/06/2015.

Date of Publishing: 11/06/2015. 